\title{
REVISED Status of drowning in Nepal: A study of central police
}

\section{data [version 2; peer review: 2 approved]}

\author{
Bhagabati Sedain (iD1, Puspa Raj Pant (iD)2 \\ ${ }^{1}$ Padma Kanya Multiple Campus, Tribhuvan University, Kathmandu, Nepal \\ ${ }^{2}$ Centre for Child and Adolescent Health, University of the West of England, Bristol, UK
}

\author{
V2 First published: 14 May 2018, 7:576 \\ https://doi.org/10.12688/f1000research.14563.1 \\ Latest published: $30 \mathrm{Jul}$ 2018, 7:576 \\ https://doi.org/10.12688/f1000research.14563.2
}

\section{Abstract}

Background: Drowning is a serious and mostly preventable injuryrelated cause of death. Low-and-middle income countries represent over $90 \%$ of total drowning deaths worldwide. There is lack of epidemiological studies of drowning in Nepal. The aim of this paper is to describe the status of drowning in Nepal.

Methods: Cases of drowning, occurring between 1 January 2013 and 31 December 2015 were extracted from the Daily Incident Recording System of Nepal Police. Drowning cases were extracted and analysed regardless of their intent. Variables on age, sex of the deceased, types of water bodies, geographical locations, season when drowning occurred and activities of deceased were extracted and descriptive analysis was conducted.

Results: A total of 1,507 drowning cases were recorded over a 3 year period. The rate of drowning was 1.9 per 100,000 (2.95 for males and 0.92 for females). Majority of drowning occurred among males (76\%) and more than half were (53\%) under 20 years of age. Mostly drowning occurred in rivers (natural water bodies). The findings provide strong indication that drowning occurs throughout the year in Nepal. Children were highly vulnerable to drowning. The magnitude of drowning was found to be lower than estimated by global burden of disease (GBD) study.

Conclusion: The burden of drowning in Nepal is considerable, but mostly unknown to the public. Despite only having access to a limited data source, this study provides useful evidence that comprehensive research in Nepal is needed urgently.

Keywords

Drowning, Nepal, Public Health, Natural water bodies, Injury

Prevention

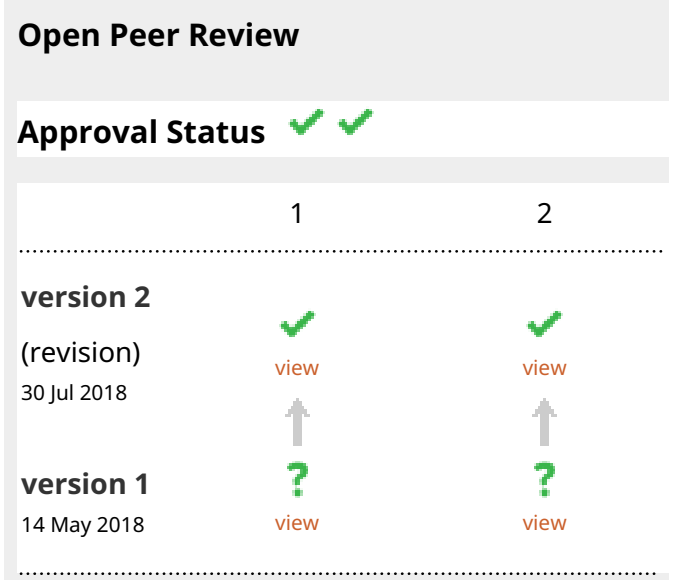

1. Amy E. Peden ID, Royal Life Saving Society Australia, Sydney, Australia

2. David Meddings, World Health Organization (WHO), Geneva, Switzerland

Any reports and responses or comments on the article can be found at the end of the article. 
Corresponding author: Bhagabati Sedain (bssedhai@gmail.com)

Author roles: Sedain B: Conceptualization, Data Curation, Formal Analysis, Methodology, Software, Validation, Visualization, Writing Original Draft Preparation; Pant PR: Conceptualization, Methodology, Supervision, Writing - Review \& Editing

Competing interests: No competing interests were disclosed.

Grant information: The author(s) declared that no grants were involved in supporting this work.

Copyright: ( $\odot 2018$ Sedain B and Pant PR. This is an open access article distributed under the terms of the Creative Commons Attribution License, which permits unrestricted use, distribution, and reproduction in any medium, provided the original work is properly cited. Data associated with the article are available under the terms of the Creative Commons Zero "No rights reserved" data waiver (CC0 1.0 Public domain dedication).

How to cite this article: Sedain B and Pant PR. Status of drowning in Nepal: A study of central police data [version 2; peer review: 2 approved] F1000Research 2018, 7:576 https://doi.org/10.12688/f1000research.14563.2

First published: 14 May 2018, 7:576 https://doi.org/10.12688/f1000research.14563.1 


\section{REVISED Amendments from Version 1}

The revised version addresses the comments provided by the reviewers. Some of the text has been revised for clarity. We have also added the map of Nepal which depicts the landscape (Mountain, Hill, and Terai) of Nepal. As suggested by the reviewer, the objectives of the study were added in the Introduction section. Some of the references were added in the Discussion section to compare the findings with the similar study. Similarly, spelling and grammatical errors in the text were also edited. We have responded to each of the reviewer's comments.

See referee reports

\section{Introduction}

Drowning is gradually being recognized as a leading cause of death in the low-and-middle-income countries (LMIC); yet it remains a neglected problem in many countries in the absence of adequate data (Peden et al., 2008; Rahman et al., 2009). The World Health Organization (WHO) estimated 372,000 deaths every year occur due to drowning, making it the world's third leading cause of fatal unintentional injuries (WHO, 2014). About $91 \%$ of the drowning deaths occur in low- and middle- income countries (Peden et al., 2008). Similarly, $40 \%$ of the world's total drowning deaths occur in children below 15 years and most of these occurred in low- and middle-income countries; $29 \%$ in South-East Asia region alone (IHME, 2016). A study from Bangladesh found the fatal drowning rate to be as high as 15.8 per 100,000 (Rahman et al., 2017).

A systematic review on epidemiology of drowning in LMICs has found that most studies on drowning were only from some countries in Asia: Bangladesh, China, India, Iran, Pakistan, Sri Lanka, Thailand and Vietnam (Tyler et al., 2017). Nepal being a mountainous country; drowning does not come instantly to mind when considering the main causes of deaths. Nepal is divided into five different physiographic regions ranging from Sub-tropical Terai (plains) in the South to High Mountains covered with snow in the North (Figure 1). These regions are often mentioned as three broad regions of Mountain, Hill and Terai in the administrative records. In Nepal, the summer monsoon season accounts for $80 \%$ of the annual rainfall, and the winter monsoon accounts for the remaining 20\% (DoHM, 2017). Flash floods, ditches, irrigation canals, and open wells are the chief hazards for drowning. Nepal has the poor coverage of vital event registration (Gautam, 2016). According to the GBD estimates, an average of 1,300 people died in 2016 from drowning in Nepal with a mortality rate of 4.0 (95\%UI 3.2 - 5.6) per 100,000 population (IHME, 2016).

Detailed community-based studies on drowning have not been conducted in Nepal; however, there are some small-scale hospital-based post-mortem reports which present the cases of drowning. Drowning was the cause of death for 5\% of total reported autopsy cases in a study of external causes of death reported in the Autopsy Centre in Kathmandu (Lunetta et al., 2004; Sharma et al., 2006). Another hospital based study found drowning as a cause of death for 144 cases out of total 205 post-mortem cases in Kathmandu during 2005 to 2010. This study also found that $39 \%$ of the drowning victims were below 18 years of age and 24\% below 11 years during 2005-2010 (Wasti et al., 2010). However, these studies only included autopsy cases referred to hospital by the police as "unnatural deaths,' which included deaths caused by drowning (Sharma et al., 2006; Wasti et al., 2010).

Similarly, an analysis of media reports on drowning deaths conducted for April 2010 to April 2011 showed that over 200 cases of drowning deaths in Nepal were reported to media, with more than half of the total drowning deaths were children (Pant et al., 2011). This study aims to discuss the status of drowning based on the officially recorded Nepal Police's information on drowning deaths as a main data source.

\section{Methods}

This study utilised drowning cases reported to Nepal Police during January 12013 to 31 December 2015. Family members or community people must report the incidents of drowning to the Daily Incidence Reporting Center of Nepal Police in each village development committee (VDC) level. Polices' database records the facts and evidence pertinent to an incident.

Police records of drowning deaths is the only national source of drowning deaths recorded in Nepal. Drowning deaths are recorded in the form of event records (narrative) including the details of the place of the residence, age, date, sex, place of drowning, type of water body, intent (intentional or accidental drowning) and activity during drowning. Both the intentional and unintentional drowning cases were analysed in this study. The described variables included; location/ geographical region, water bodies, months of drowning were also extracted, entered and analysed using SPSS version 16.0.

Descriptive study was performed in order to show the distribution of fatal drowning by age, gender, type of water body, months of the year, geographical location, and activity of the victim before the drowning incident. Possible core victim identifiers i.e. age, gender, date, activity and location of the incident and describing variables i.e. water bodies, months of drowning, and activity before drowning were also analysed and described. Information about the 'time', 'distance' from the victim's home and the companion were not available in the database.

\section{Ethics}

Ethical approval was not required for this study, because it did not involve human participants. This study used secondary data registered by police. To access the data the request latter on behalf of Tribhuvan University, Padma Kanya Campus was submitted to the Crime Investigation Department. As per the request, the police department granted accesses to the police record. In this study, personal identifiers or confidential information of deceased were not disclosed.

\section{Results}

This study identified 1,507 cases of drowning deaths in three years (2013-2015). Among these drowning cases highest deaths were in Terai (low land) 700 (46.4\%). Drowning deaths were found to vary between geographical regions (Table 1). Most of 


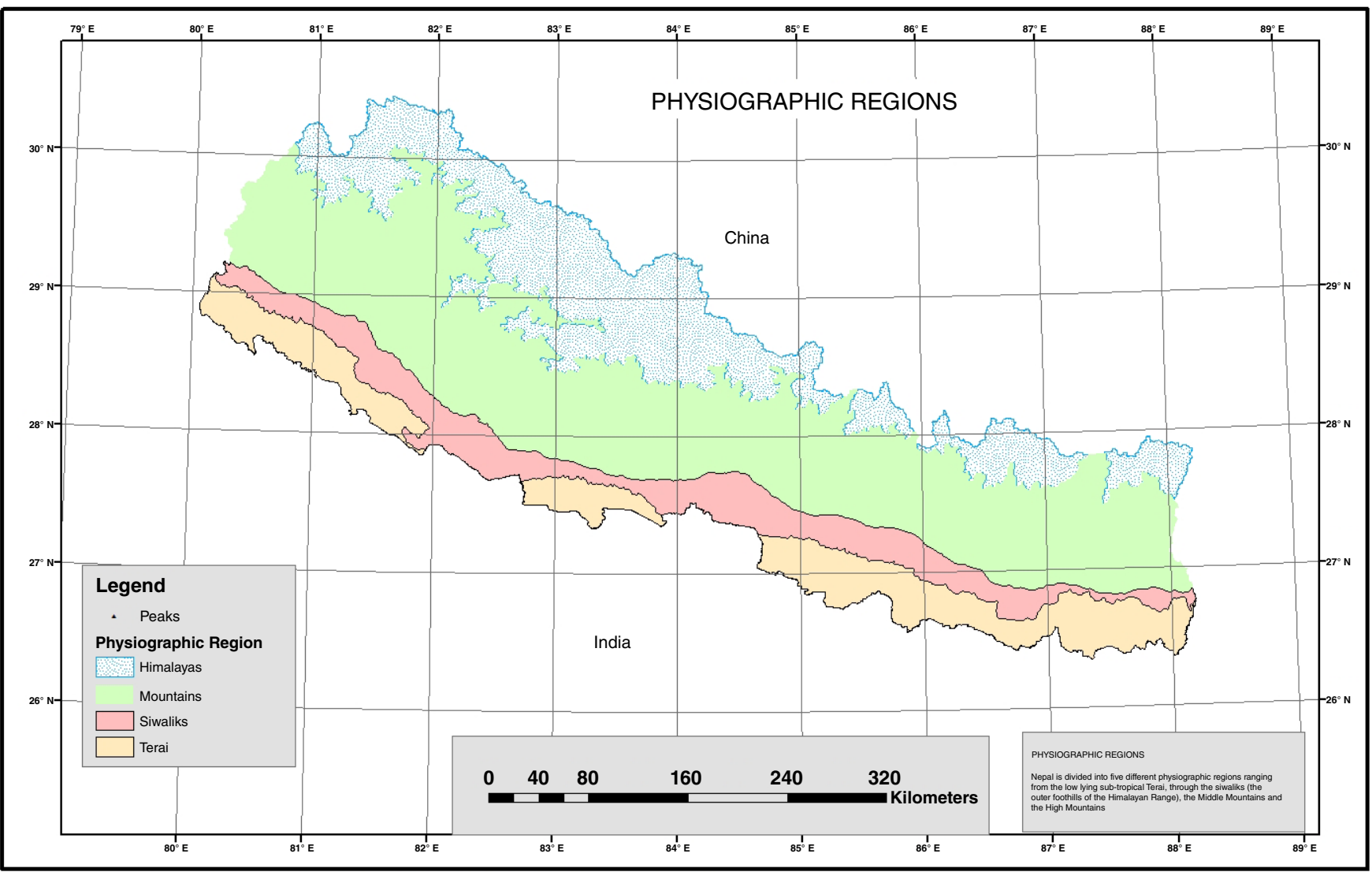

Figure 1. Map of Nepal indicating geographical regions. Reproduced with permission from the Survey Department, Ministry of Agriculture, Land Management and Cooperative.

\begin{tabular}{|c|c|}
\hline Geographical region & Number (\%) \\
\hline Mountain & $228(15.1)$ \\
\hline Hill & $579(38.4)$ \\
\hline Terai & $700(46.4)$ \\
\hline Total & $1507(100.0)$ \\
\hline
\end{tabular}

the drowning deaths in Nepal occurred in the natural water bodies. The highest number of drowning deaths were observed in the Plains followed by the Hills.

The proportion of males that died from drowning was higher than females. Table 2 shows the sex differentials in drowning deaths. Younger people $(<20$ years $)$ comprised over half of the drowning deaths, making up $52.7 \%$ of all drowning deaths. Similarly, age specific drowning deaths were higher for 10-19 years closely followed by 0-9 years and then declined as the age increases. The most common drowning age was 10-19 years for males and 0-9 years for females. Age reporting was missing for 27 cases.
This study also identified a seasonal pattern of drowning, which showed high incidents of drowning during monsoon season, with peaks in July, with the winters (December-January) being relatively low for drowning. The monsoon season (June - August) claimed about $43 \%$ of the total drownings and over $15 \%$ drownings occurred in the summer season i.e. during April-May (Figure 2).

More than $88 \%$ of the drowning deaths occurred in natural bodies of water. Rivers, ponds and lakes were most common places for drowning in Nepal (Table 3). A smaller proportion of drowning also occurred in man-made water containing bodies like canals, water-filled pits, safety tanks, water tanks, and wells.

Swimming, bathing, and crossing the river were the mostly reported activities before drowning, and occurring mainly in the summer season. In Nepal, whether people go near the river, bathe by the bank or go into the water for swimming depends upon age, gender and location of the river. Activity before drowning for 181 (12\%) cases were not mentioned at all (Table 4).

Dataset 1. Data file containing drowning data gathered from police records

http://dx.doi.org/10.5256/f1000research.14563.d202804 
Table 2. Drowning deaths compared by age and sex for the period 2013-2015.

\begin{tabular}{|c|c|c|c|}
\hline \multirow{2}{*}{$\begin{array}{l}\text { Age group } \\
\text { (years) }\end{array}$} & \multicolumn{2}{|c|}{ Sex } & \multirow[b]{2}{*}{ Total } \\
\hline & $\begin{array}{c}\text { Male } \\
\text { Number (\%) }\end{array}$ & $\begin{array}{c}\text { Female } \\
\text { Number (\%) }\end{array}$ & \\
\hline $0-9$ & $211(18.8 \%)$ & $117(32.8)$ & $328(22.2 \%)$ \\
\hline $10-19$ & 351 (31.3\%) & $100(28.0 \%)$ & $451(30.5 \%)$ \\
\hline 20-29 & $196(17.5 \%)$ & $40(11.2 \%)$ & 236 (15.9\%) \\
\hline 30-39 & 109 (9.7\%) & $40(11.2 \%)$ & $149(10.1 \%)$ \\
\hline $40-49$ & $100(8.9 \%)$ & $22(6.2 \%)$ & $122(8.2 \%)$ \\
\hline $50-59$ & $66(5.9 \%)$ & $18(5.0 \%)$ & $84(5.7 \%)$ \\
\hline $60-69$ & $53(4.7 \%)$ & $12(3.4 \%)$ & 65 (4.4\%) \\
\hline $70-79$ & $29(2.6 \%)$ & $5(1.3 \%)$ & $34(2.3 \%)$ \\
\hline 80-89 & $8(0.6 \%)$ & $1(0.3 \%)$ & $9(0.6 \%)$ \\
\hline 90-99 & $0(0 \%)$ & $2(0.6 \%)$ & $2(0.1 \%)$ \\
\hline Total ${ }^{\S}$ & $1,123(100 \%)$ & 357 (100\%) & $1,480(100 \%)$ \\
\hline
\end{tabular}

§Age was not recorded for 27 cases

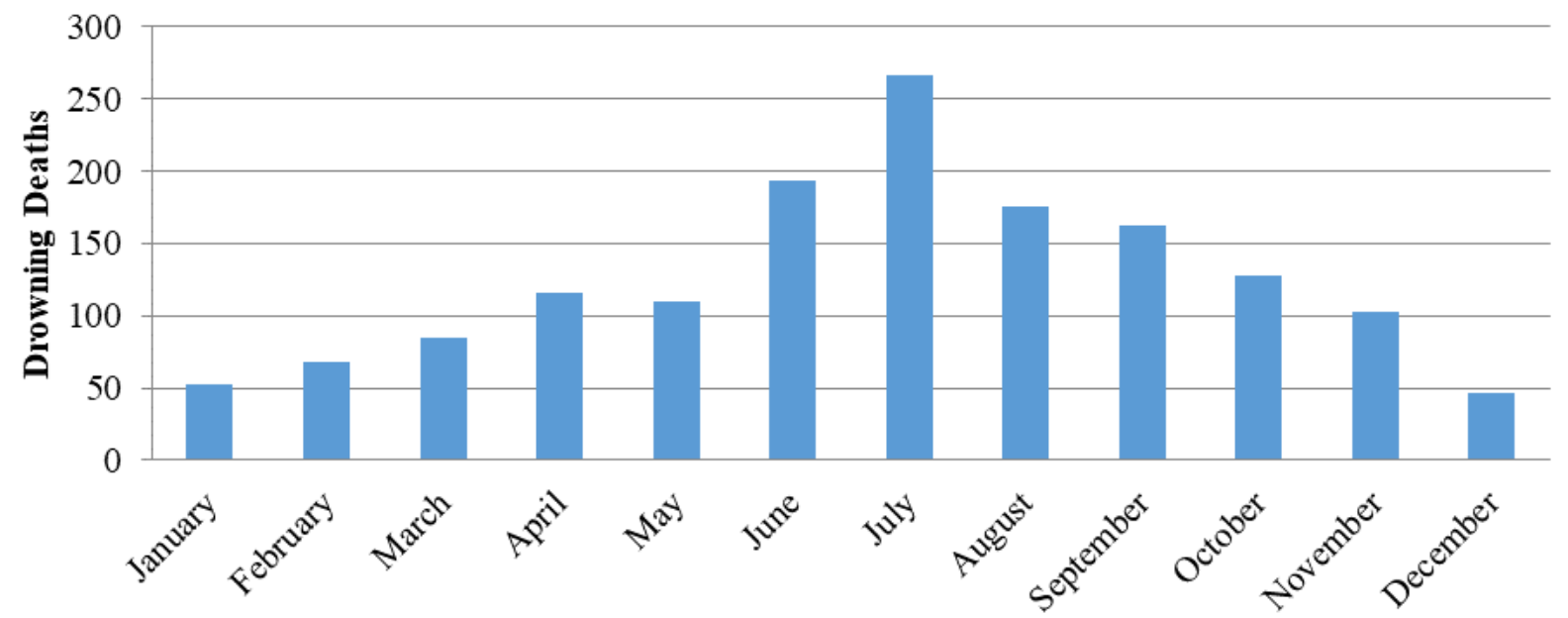

Month

Figure 2. Percentage distribution of drowning cases by month ( $n-1507)$.

\section{Discussions}

A systematic review on fatal river drownings showed that river drowning deaths are an issue in many regions and countries around the world (Peden et al., 2016; Rahman et al., 2009). Similarly, epidemiological study conducted in Australia elucidated natural water bodies account for large proportion of drowning deaths (Peden et al., 2016). However, there has been limited research that has explored drowning in locations other than beaches and swimming pools. Natural water bodies such as rivers, streams and lakes regularly account for large proportions of drowning deaths (Peden et al., 2016; Rahman et al., 2017). Drowning, along with other injuries is neglected in Nepal. Most of the drowning occur in the natural water bodies such as rivers, canals, streams, lakes. In the plains, the number of drowning deaths were high although it was proportional to the population size. Nature of water bodies and landscape are different in three (Mountain, Hill and Terai) geographical regions, same as that the risk factors vary by geographical regions. Similarly, more than half of the drowning deaths occur in Hilly and Mountain regions. 
Table 3. Distribution by place of drowning for the period 2013-2015.

\begin{tabular}{|l|r|}
\hline Source of drowning & Number (\%) \\
\hline River & $1195(79.3 \%)$ \\
\hline Pond & $114(7.6 \%)$ \\
\hline Canal & $82(5.4 \%)$ \\
\hline Lake & $19(1.3 \%)$ \\
\hline Water-filled pits & $66(4.4 \%)$ \\
\hline Safety tank & $5(0.3 \%)$ \\
\hline Water tank & $7(0.5 \%)$ \\
\hline Wells & $14(0.9 \%)$ \\
\hline Others & $5(0.3)$ \\
\hline Total & $\mathbf{1 5 0 7 ( 1 0 0 \% )}$ \\
\hline
\end{tabular}

Table 4. Distribution of deaths by activity before drowning for the period 2013-2015.

\begin{tabular}{|l|r|}
\hline Activity & Number (\%) \\
\hline Bathing & $222(14.7 \%)$ \\
\hline Swimming & $269(17.9 \%)$ \\
\hline Crossing river & $244(16.3 \%)$ \\
\hline Accidently falling & $211(14.0 \%)$ \\
\hline Fishing/boating & $110(7.3 \%)$ \\
\hline Suicide & $109(7.2 \%)$ \\
\hline Playing in the water source & $101(6.7 \%)$ \\
\hline Falling from bridge & $45(2.9 \%)$ \\
\hline Water-filled pits/pond/dam & $15(1.0 \%)$ \\
\hline Others & $181(12.0 \%)$ \\
\hline Total & $\mathbf{1 5 0 7 ( 1 0 0 \% )}$ \\
\hline
\end{tabular}

१Others were the cases where activity before drowning were not clearly mentioned

A study by Pant and colleagues (Pant et al., 2011) has a number of limitations; even though that demonstrated a similar type of results reported in this paper. Nepal is mountainous country, rivers are the major natural water body and rivers accounted for the largest number of fatal drownings $(80 \%)$ for the period between 2013 and 2015. This was unlike other studies from LMICs (Hyder et al., 2009; Rahman et al., 2009; Soko, 2012) where most of the drownings occurred in wells, water storage facilities or reservoirs, ditches and drains.

The monsoon season in Nepal takes place during the months of June-September when $80 \%$ of the yearly rainfall occurs throughout the country. During the months of April - June (summer), it is very warm during the day and more people use rivers, streams or other water bodies for swimming and bathing. Drownings occur while performing these activities. However, it was found drowning deaths occur throughout the year.
In the absence of household pipe water supplies and bridges, people are forced to be in contact with these unprotected water bodies every day. Data revealed that drowning often occurs as a result of the activities associated with daily life i.e. bathing, crossing river and fishing in the river. Surprisingly, no cases were reported to have drowned while fetching water which implies the need for more in-depth research.

Drowning varies greatly with age (Pant et al., 2011; Quan \& Cummings, 2003). This study also revealed that drowning is more common in children rather than older age groups. A similar finding has also been highlighted in several global (World Health Organization, 2014), regional (Quan \& Cummings, 2003; World Health Organization, 2014) and country level studies (Pant et al., 2011; Rahman et al., 2017). Drowning due to accidental falls mostly occurred in $0-4$ year old children. These findings were similar to the study by Royal Life Saving Society in Australia (RLSSA, 2016). This study also found that drowning claimed more lives of children below 18 years than adults.

Similarly, the proportion of drowning deaths were higher among males. Roughly three times as many deaths were reported in male versus female, which is similar to the findings of WHO's Global Report on Drowning (Rahman et al., 2017; Soko, 2012; World Health Organization, 2014; World Health Organization, 2014). A study on alcohol and its contributory role in fatal drowning in Australian rivers found that the alcohol consumption among male increased fatal drowning (Peden et al., 2017). The higher male drowning might be due to increased exposure to water and riskier behaviour. Findings show that female drowning was common in early ages (less than 9 years) and for the male it was high during the age 10-19 years. Overall, males of all ages outnumbered females for drowning.

These patterns of drowning in terms of age, gender, places of drowning, activity before drowning and seasonal patterns are consistent with findings of studies elsewhere (IHME, 2016; Pant et al., 2011; Peden et al., 2016). Further study is needed to identify the tendency to exposure and age-related drowning by activity before drowning.

\section{Strengths}

The strength of the study is that nationally recorded information from the Nepal Police was obtained. To our knowledge, this is the first study that attempted to study about drowning throughout the country which is able to present the patterns of drowning by district, age, gender and place of occurrence.

\section{Limitations}

Information was limited to those drowning cases reported within 24 hours of occurrence through the daily incident reporting system of Nepal Police. This information doesn't take into account those who have gone missing into water. So, this study underreports drowning in Nepal. There is a lack of information on distance from home, time of the event, person accompanying the victims, and intent and influence of substances or illness responsible for the drowning incidents, which can be very helpful for designing drowning prevention interventions. 
The data collected by the police was not be for the purpose of drowning prevention rather was for a forensic investigation or criminality. Some of the reported variables were incomplete (i.e. age of the person, location of drowning etc.). The data used in this manuscript has very limited information for every component of: a) victim information, b) scene information, c) any emergency medical services provided, and d) any Hospital care received by the victim.

\section{Conclusion}

The findings of this study suggest that drowning occurs in many parts of Nepal and not necessarily only in the plains; and children are highly vulnerable to drowning. Rivers were the most common place of drowning in Nepal and the rate of drowning increased in rainy season. There is a need for better understanding of people's contact with rivers by gender and age to inform prevention.

\section{Data availability}

Dataset 1: Data file containing drowning data gathered from police records 10.5256/f1000research.14563.d202804 (Sedain \& Pant, 2018)

\section{Competing interests}

No competing interests were disclosed.

\section{Grant information}

The author(s) declared that no grants were involved in supporting this work.

\section{Acknowledgements}

The authors would like to thank the Office In-charge of the Crime Investigation Department of Nepal Police who kindly provided access to the data.
Department of Hydrology and Meteorology (DoHM): Observed climate trend analysis of Nepal (1971-2014). Department of Hydrology and Meteorology. 2017. Reference Source

Gautam BR: Civil registration and vital statistics: policy and practices in Nepal. Department of Civil Registration, Babarmahal, Kathmandu, Nepal, 2016.

Reference Source

Hyder AA, Sugerman DE, Puvanachandra P, et al.: Global childhood unintentional injury surveillance in four cities in developing countries: a pilot study. Bull World Health Organ. 2009; 87(5): 345-352.

PubMed Abstract | Publisher Full Text | Free Full Text

IHME: Global Burden of Disease Study 2015. (GBD 2015) Results. 2016. Reference Source

Lunetta P, Smith GS, Penttilä A, et al.: Unintentional drowning in Finland 1970-2000: a population-based study. Int J Epidemiol. 2004; 33(5): 1053-1063. PubMed Abstract | Publisher Full Text

Pant PR, Baset K, Towner E: Fatal drownings in Nepal: As reported in the media, 2011. Abstract World Conference on Drowning Prevention, 2010. International Lifesaving Federation. 2011.

Reference Source

Peden AE, Franklin RC, Leggat PA: Fatal river drowning: the identification of research gaps through a systematic literature review. Inj Prev. 2016; 22(3): 202-209.

PubMed Abstract | Publisher Full Text | Free Full Text

Peden AE, Franklin RC, Leggat PA: The Hidden Tragedy of Rivers: A Decade of Unintentional Fatal Drowning in Australia. PLOS One. 2016: 11(8): e0160709. PubMed Abstract | Publisher Full Text | Free Full Text

Peden AE, Franklin RC, Leggat PA: Alcohol and its contributory role in fata drowning in Australian rivers, 2002-2012. Accid Anal Prev. 2017: 98: 259-265. PubMed Abstract | Publisher Full Text

Peden M, Oyegbite K, Ozanne-Smith J, et al.: World Report on Child Injury Prevention. Geneva. 2008.

PubMed Abstract

Quan L, Cummings P: Characteristics of drowning by different age groups.
Inj Prev. 2003; 9(2): 163-168.

PubMed Abstract | Publisher Full Text | Free Full Text

Rahman A, Alonge O, Bhuiyan AA, et al.: Epidemiology of Drowning in Bangladesh: An Update. Int J Environ Res Public Health. 2017; 14(5): pii: E488.

PubMed Abstract | Publisher Full Text | Free Full Text

Rahman A, Mashreky SR, Chowdhury SM, et al:: Analysis of the childhood fatal drowning situation in Bangladesh: exploring prevention measures for lowincome countries. Inj Prev. 2009; 15(2): 75-79.

PubMed Abstract | Publisher Full Text

Royal Life Saving Society Australia (RLSSA): Royal Life Saving National Drowning Report. 2016.

Reference Source

Sedain B, Pant PR: Dataset 1 in: Status of drowning in Nepal: A study of centra police data. F1000Research. 2018.

http://www.doi.org/10.5256/f1000research.14563.d202804

Sharma G, Shrestha PK, Wasti $\mathrm{H}$, et al:: A review of violent and traumatic deaths in Kathmandu, Nepal. Int J Inj Contr Saf Promot. 2006; 13(3): 197-199.

PubMed Abstract | Publisher Full Text

Soko B: Fiji Drowning Report 2012. Suva. 2012

Reference Source

Tyler MD, Richards DB, Reske-Nielsen C, et al: The epidemiology of drowning in low- and middle-income countries: a systematic review. BMC Public Health 2017; 17(1): 413

PubMed Abstract | Publisher Full Text | Free Full Text

Wasti $\mathrm{H}$, Lunetta $\mathrm{P}$, Chaudhary G: Epidemiological profile of drowning in Nepal. Preliminary data from the Kathmandu region, 19127447. 2010.

Reference Source

World Health Organization: Global report on drowning: Preventing a leading killer. Geneva. 2014

Reference Source

World Health Organization: World Health Organization. Drowning Prevention in the South-East Asia Region-2014. New Delhi. 2014

Reference Source 


\section{Open Peer Review}

\section{Current Peer Review Status:}

\section{Version 2}

Reviewer Report 28 August 2018

https://doi.org/10.5256/f1000research.16953.r36594

(C) 2018 Meddings D. This is an open access peer review report distributed under the terms of the Creative Commons Attribution License, which permits unrestricted use, distribution, and reproduction in any medium, provided the original work is properly cited.

\section{David Meddings}

Department for Management of Noncommunicable Diseases, Disability, Violence and Injury Prevention (NVI), World Health Organization (WHO), Geneva, Switzerland

The revised version is improved significantly and I am fine to approve it now without reservations.

Competing Interests: No competing interests were disclosed.

I confirm that I have read this submission and believe that I have an appropriate level of expertise to confirm that it is of an acceptable scientific standard.

Reviewer Report 13 August 2018

https://doi.org/10.5256/f1000research.16953.r36593

(C) 2018 Peden A. This is an open access peer review report distributed under the terms of the Creative Commons Attribution License, which permits unrestricted use, distribution, and reproduction in any medium, provided the original work is properly cited.

\section{Amy E. Peden}

Royal Life Saving Society - Australia, Sydney, NSW, Australia

Thank you for the chance to review the revised article. The authors have addressed my concerns sufficiently. I congratulate them on this important work on adding to the scant body of the literature on drowning in Nepal.

Competing Interests: No competing interests were disclosed.

I confirm that I have read this submission and believe that I have an appropriate level of expertise to confirm that it is of an acceptable scientific standard. 


\section{Version 1}

Reviewer Report 16 May 2018

\section{https://doi.org/10.5256/f1000research.15850.r34006}

(C) 2018 Meddings D. This is an open access peer review report distributed under the terms of the Creative Commons Attribution License, which permits unrestricted use, distribution, and reproduction in any medium, provided the original work is properly cited.

\section{David Meddings}

Department for Management of Noncommunicable Diseases, Disability, Violence and Injury Prevention (NVI) , World Health Organization (WHO), Geneva, Switzerland

Thank you for the opportunity to review this paper.

\section{General comments}

1. The paper is an important and useful contribution, as there is very little in the peerreviewed literature about drowning in Nepal.

2. The authors should go into more detail about the police data source they used - particularly whether there are estimates of the number of deaths that occur but which are not reported to this source, whether there are biases etc.

3. The presentation of results seems somewhat haphazard - the authors could benefit from taking one step back from their data and deciding what are the 3-5 main findings we have come across here that are important and deserve to be amplified and framed clearly for the reader.

4. There is little in the way of serious follow up discussion on some aspects that would seem to invite more critical thinking - the disparity between this study's findings and GBD estimates for example.

5. There are numerous spelling and grammatical errors in the text, so this should be edited prior to publication.

\section{Specific comments}

1. Results section - drop "the open water" - which could be confused as meaning waters far from any coastline - and replace with either natural water bodies or rivers.

2. Proportion of males is cited as being higher than females - it is simple enough to give this as "roughly 3 times as many deaths were reported in males versus females", or words to that effect. It communicates with greater precision one of the findings of interest.

3. I take the seasonality pattern but believe there is somewhat muddled writing about the effect of seasons here. Clearly there are some drownings that occur year round, but the authors should be clear on drawing attention to the surge during the monsoon season as this has implications for prevention programmes.

4. The references appear incomplete - for example, the Global Report on Drowning from the WHO is referenced within the body of the text but does not appear within the references, although a WHO regional report does.

Is the work clearly and accurately presented and does it cite the current literature? 
Partly

Is the study design appropriate and is the work technically sound?

Yes

Are sufficient details of methods and analysis provided to allow replication by others? Partly

If applicable, is the statistical analysis and its interpretation appropriate?

Not applicable

Are all the source data underlying the results available to ensure full reproducibility? Yes

Are the conclusions drawn adequately supported by the results?

Yes

Competing Interests: No competing interests were disclosed.

I confirm that I have read this submission and believe that I have an appropriate level of expertise to confirm that it is of an acceptable scientific standard, however I have significant reservations, as outlined above.

Reviewer Report 15 May 2018

https://doi.org/10.5256/f1000research.15850.r34009

(C) 2018 Peden A. This is an open access peer review report distributed under the terms of the Creative Commons Attribution License, which permits unrestricted use, distribution, and reproduction in any medium, provided the original work is properly cited.

\section{Amy E. Peden}

Royal Life Saving Society - Australia, Sydney, NSW, Australia

Thank you for the opportunity to review the article entitled "Status of drowning in Nepal: A study of central police data". This is a well-written study detailing drowning in a country with little previous published research, using a novel data source being police data.

I have some general comments for the authors that I hope they find useful.

For someone unfamiliar with the geography of Nepal, I suggest adding a map as an additional figure that depicts the regions in Table 1 (Terai, Plains and Hills) geographically.

You need to clarify somewhere in the methods (and abstract) that this is all drowning, both intentional and unintentional. 
I also have some specific comments for the authors as follows:

Abstract - Methods - can you specify the dates of the study - e.g. 1 January 2013 and 31 December 2015

Abstract - Methods - can you confirm what places means? Its not aquatic locations so is it geographical location within Nepal?

Abstract - Methods - suggest replacing 'done' with 'undertaken' or 'conducted'

Main manuscript - Introduction - this study needs a clearer aim - the sentence that currently ends the introduction may be about the study referenced before. A clearer aim e.g. this study aims to .... Using police report as the main data source, with media reports as a secondary source of data..

Methods - how many don't report to police? Add to limitations.

Methods - again confirm what place of drowning means if not type of body of water

Ethics - usually even though the participants are deceased, this research would be considered as including human participants and ethics would be required. Is it possible to get ethics approval retrospectively? It is definitely helpful that you specify that the data received was de-identified.

Results - can a definition for the term 'open water' as per the first paragraph of the results be added to the methods?

Discussion - 'systemic' should be 'systematic'.

Discussion - please also cite dedicated epidemiological study of rivers that have been conducted in Australia ${ }^{1}$. These further support the statement that natural water bodies such as rivers regularly account for large proportions of drowning deaths.

Discussion - when discussing riskier behaviour in males - you might want to note the involvement of alcohol (see Peden et al. $(2017)^{2}$ ). I'm not sure whether alcohol is a big issue in Nepal, and I note there was no toxicological data from police supporting or disproving alcohol involvement but it might be worth mentioning as an additional area of research for drowning in Nepal, especially among males.

Strengths - By using police records, you also avoid issues with traditional ICD drowning codes (W65-74) not capturing all drownings (see Peden et al. $(2017)^{3}$ ). This is a strength of the study.

Limitations - are there ever cases of people not reporting a drowning at all or not reporting it within 24 hours? If so this study likely underreports drowning in Nepal and this would be worth mentioning.

\section{References}


1. Peden AE, Franklin RC, Leggat PA: The Hidden Tragedy of Rivers: A Decade of Unintentional Fatal Drowning in Australia.PLoS One. 2016; 11 (8): e0160709 PubMed Abstract | Publisher Full Text 2. Peden AE, Franklin RC, Leggat PA: Alcohol and its contributory role in fatal drowning in Australian rivers, 2002-2012.Accid Anal Prev. 2017; 98: 259-265 PubMed Abstract | Publisher Full Text

3. Peden A, Franklin R, Mahony A, Scarr J, et al.: Using a retrospective cross-sectional study to analyse unintentional fatal drowning in Australia: ICD-10 coding-based methodologies verses actual deaths. BMJ Open. 2017; 7 (12). Publisher Full Text

Is the work clearly and accurately presented and does it cite the current literature? Partly

Is the study design appropriate and is the work technically sound? Yes

Are sufficient details of methods and analysis provided to allow replication by others? Yes

If applicable, is the statistical analysis and its interpretation appropriate? Yes

Are all the source data underlying the results available to ensure full reproducibility? Yes

Are the conclusions drawn adequately supported by the results?

Yes

Competing Interests: No competing interests were disclosed.

I confirm that I have read this submission and believe that I have an appropriate level of expertise to confirm that it is of an acceptable scientific standard, however I have significant reservations, as outlined above.

Author Response 11 Jul 2018

Bhagabati Sedain, Tribhuvan University, Kathmandu, Nepal

For someone unfamiliar with the geography of Nepal, I suggest adding a map as an additional figure that depicts the regions in Table 1 (Terai, Plains and Hills) geographically. Author's response: Thank you! We found your comment extremely helpful and have revised accordingly.

You need to clarify somewhere in the methods (and abstract) that this is all drowning, both intentional and unintentional.

Author's Response: Both the intentional and unintentional drowning deaths were analysed in this study. So, in this revised paper, it is clearly mentioned that the study included both the intentional and unintentional drowning deaths. 
I also have some specific comments for the authors as follows:

Abstract - Methods - can you specify the dates of the study - e.g. 1 January 2013 and 31 December 2015

Author's Response: We also realised it is better to mention the study date in such way and have revised accordingly.

Abstract - Methods - can you confirm what places means? Its not aquatic locations so is it geographical location within Nepal?

Author's Response: In the study, the places means the geographical locations i.e. Mountain, Hill and Terai. Instead of places, the term geographical location is used in the revised paper.

Abstract - Methods - suggest replacing 'done' with 'undertaken' or 'conducted'

Author's Response: We really appreciated your comments and since terminology would be more accurate and precise, we have taken your advice.

Main manuscript - Introduction - this study needs a clearer aim - the sentence that currently ends the introduction may be about the study referenced before. A clearer aim e.g. this study aims to .... Using police report as the main data source, with media reports as a secondary source of data..

Author's Response: The study used police report as the main source of data. Objectives of the study was mentioned in the abstract. We also noticed that the objective of the study was missing in the introduction section of the main text. At the end of the introduction of the main text, the objective of the study is stated in the revised article.

Methods - how many don't report to police? Add to limitations.

Author's Response: Review of literature showed that larger number of unnatural deaths were not reported in the police. As Nepal is a less developed country, there is the high probability of people not reporting the unnatural deaths to the police. So, it is challenging to discuss on the missing cases. In case of drowning deaths, Nepal Police's record is the only one source information.

Methods - again confirm what place of drowning means if not type of body of water Author's Response: The word drowning place was mistakenly written in the main text so it is deleted.

Ethics - usually even though the participants are deceased, this research would be considered as including human participants and ethics would be required. Is it possible to get ethics approval retrospectively? It is definitely helpful that you specify that the data received was de-identified.

Author's Response: Ethical approval was obtained from University Review Committee. We used secondary data which was completely de-identified right from Data Extraction which was done on the Police Office premises. No identifiable data for the deceased person was transferred by any means.

Results - can a definition for the term 'open water' as per the first paragraph of the results 
be added to the methods?

Author's Response: Thank you for this excellent observation. Both of the reviewers commented on this word 'open water'. So the word replace with natural water bodies. Discussion - 'systemic' should be 'systematic'.

Author's Response: It was a typo in the manuscript and changed accordingly.

Discussion - please also cite dedicated epidemiological study of rivers that have been conducted in Australia1. These further support the statement that natural water bodies such as rivers regularly account for large proportions of drowning deaths.

Author's Response: We agree that it will be better if it was included in the discussion. We have added the suggested reference in the discussion section.

Discussion - when discussing riskier behaviour in males - you might want to note the involvement of alcohol (see Peden et al. (2017)2). I'm not sure whether alcohol is a big issue in Nepal, and I note there was no toxicological data from police supporting or disproving alcohol involvement but it might be worth mentioning as an additional area of research for drowning in Nepal, especially among males.

Author's Response: In the police record, the use alcohol use was not clearly mentioned. However, there is the high prevalence of drinking behaviour among the male. So we are grateful to know about this article and it was realised that the adding of the suggested reference would validate our result. So the suggested reference has been included in the revised manuscript.

Limitations - are there ever cases of people not reporting a drowning at all or not reporting it within 24 hours? If so this study likely underreports drowning in Nepal and this would be worth mentioning.

Author's Response: . There is high possibility of not reporting all deaths within $24 \mathrm{hrs}$. The information recorded in the Nepal Police through daily incidence reporting system was analysed in this study. It is likely to observe underreporting of the drowning deaths. In the revised manuscript this issue is clearly mentioned in the limitation section.

Competing Interests: No competing interest 
The benefits of publishing with F1000Research:

- Your article is published within days, with no editorial bias

- You can publish traditional articles, null/negative results, case reports, data notes and more

- The peer review process is transparent and collaborative

- Your article is indexed in PubMed after passing peer review

- Dedicated customer support at every stage

For pre-submission enquiries, contact research@f1000.com 